\title{
Vocational Rehabilitation Professionals' Perceptions of Facilitators and Barriers to Return to Work: A Qualitative Descriptive Study
}

Rehabilitation Counseling Bulletin I-13

(C) Hammill Institute on Disabilities 2021 (c) (i)

Article reuse guidelines: sagepub.com/journals-permissions DOI: I0.1 I77/003435522II060013 rcb.sagepub.com (SSAGE

\author{
Kjerstin Larsson, PhD', Anna Liljestam Hurtigh, RN ${ }^{2}$, \\ Åsa M. V. Andersén, $\mathbf{P h D}^{\prime}$, and Ingrid Anderzén, $\mathbf{P h D}^{\prime}$
}

\begin{abstract}
This is a qualitative descriptive study of professionals' perceptions of facilitators and barriers for returning to work for women on long-term sick leave due to musculoskeletal pain and/or common mental disorder who participated in a vocational rehabilitation project. Data were collected through semi-structured interviews with I 3 purposefully selected professionals from the Swedish Social Insurance Agency, the Swedish Public Employment Service, the health care services, and the municipal services. The interviews were analyzed with a manifest content analysis. The main facilitators were the close cooperation between the professionals and the individual support that was offered to the project participants. The main barriers were differences among the stakeholders' missions and goals, limitation in project duration and within the labor market, and the project participants' personal factors. These results emphasize the importance of cooperation between the professionals from the various stakeholders and focus on the individual's resources and needs. The study highlights the value of including health care professionals in vocational rehabilitation to benefit from their specific knowledge of the target group and their strengths and needs. Moreover, the study highlights the need to incorporate collaboration with employers and align with the local labor market in the development of vocational rehabilitation interventions.
\end{abstract}

\section{Keywords}

facilitators, barriers, return to work, women, sick leave, rehabilitation, qualitative

Vocational rehabilitation in Sweden involves several stakeholders, including the Swedish Social Insurance Agency (SSIA), the Swedish Public Employment Service (SPES), health care services, employers, and municipalities' social services. The responsibility for vocational rehabilitation is shared between these stakeholders.

The SSIA investigates the need for vocational rehabilitation measures, assesses the ability to work, and coordinates efforts with the other stakeholders to facilitate return to work (RTW) or job-seeking. The health care services are responsible for the medical rehabilitation, and the employer's responsibility is work-oriented measures such as workplace adaptations and support to the individual in the RTW process (SSIA, 2021). The SPES (2021) can investigate needs and offer guidance and introduction to work or placements for work training for people who have the ability to work. The SSIA, SPES, health care services, social services, and employers are commissioned to cooperate within the vocational rehabilitation to support the individual to become self-sufficient (SSIA, 2021).
However, the necessary interaction between organizational boundaries is complex, and a number of factors have proven to act as threats to the organizational cooperation (Loisel \& Anema, 2013). These factors include the various agendas of the rehabilitation stakeholders, different working methods, and administrative restrictions (Andersson et al., 2010). Moreover, the absence of joint values, goals, and working methods among these stakeholders is reported to limit the dialogue between those involved, thus impeding the vocational rehabilitation for the individual (Johansson et al., 2010).

\footnotetext{
'Uppsala University, Sweden

${ }^{2}$ Uppsala University Hospital, Sweden

Corresponding Author:

Kjerstin Larsson, Department of Public Health and Caring Sciences, Health Equity and Working Life, Uppsala University, Box 564, 75237 Uppsala, Sweden.

Email: kjerstin.larsson@pubcare.uu.se
} 
Public organizations' experiences of participating in cooperative actions in the area of vocational rehabilitation illustrate the complexity of cooperation (Ståhl et al., 2010, 2011). The motives and goals for cooperation differed between the involved organizations, and employees acting in accordance with the goals of their own organization without regard to the goals of partner agencies may inadvertently hinder cooperation. Moreover, inability of managers to implement cooperation in regular practice in combination with inflexible regulations threatens the cooperation between the organizations (Ståhl et al., 2010, 2011).

Swedish social insurance professionals and employers' perspectives of factors connected to cooperation in the vocational rehabilitation process have been found to be consistent in their views of the rehabilitation process (Gard \& Larsson, 2006; Gard \& Söderberg, 2004). The social insurance professionals stated that the most important factors for improved vocational rehabilitation were close cooperation, information, and knowledge exchange between the rehabilitation stakeholders; early identification of the individual's problems and needs; clear goal formulations; focus on psychosocial factors; use of a variety of interventions; and activation of employers in the process (Gard \& Söderberg, 2004). The employers stated similar factors as most important for improved cooperation with rehabilitation professionals, including those employed within the social insurances, such as early identification of rehabilitation needs, prevention, and intervention; knowledge of each other's roles, responsibilities, and opportunities; prioritizing; and increased focus on each part's own responsibilities (Gard \& Larsson, 2006).

There is a lack of practice-based research from the perspective of vocational rehabilitation professionals, especially regarding research on RTW for women on long-term sick leave due to pain and/or common mental disorders. Women have been on sick leave more often and for longer periods than men, in both Sweden and other Western European countries for the past 30 years (Angelov et al., 2011; Deutreux \& Viksten, 2004; SSIA, 2007, 2015). Leading causes for long-term sick leave (defined as sick leave for 60 days or longer) are common mental disorders, musculoskeletal pain, and comorbidity between these disorders (Fishbain et al., 1997; Henderson et al., 2011; Linder et al., 2009; SSIA, 2007, 2015).

To support RTW for women on long-term sick leave due to musculoskeletal pain and/or common mental disorder, an intervention and cooperation project (the Vitalis project) was developed in Uppsala County, Sweden. The Vitalis project is further presented in the "Setting" section. The results of the Vitalis project showed that the women who received the acceptance and commitment therapy (ACT) intervention increased their chances of employability compared with the control group (Berglund et al., 2018). Furthermore, those who took part in the multidisciplinary team assessments and interventions (TEAM) increased their chances of both employability and RTW (Lytsy et al., 2017).

In contrast to earlier publications about the Vitalis project (Andersén et al., 2015, 2018a; Berglund et al., 2018; Finnes et al., 2021; Lytsy et al., 2017), the focus of this study is on the experiences and perceptions of the professionals connected to the project. Thus, the aim of this study was to explore and describe the vocational rehabilitation professionals' perceptions of facilitators and barriers for RTW for women on long-term sick leave due to musculoskeletal pain and/or common mental disorder who participated in the Vitalis project.

\section{Method}

\section{Study Design}

This qualitative descriptive study collected data through semi-structured interviews. The design was chosen because of its suitability in the study of people's thoughts and experiences (Kvale \& Brinkmann, 2009).

\section{Setting}

This interview study was performed within the frames of a three-armed randomized controlled trial, the Vitalis project, which was carried out at the Department for Vocational Rehabilitation at a university hospital. The project aimed to support RTW for women on long-term sick leave due to musculoskeletal pain and/or common mental disorder. The women included in the project were expected to reach their maximum limit of sickness compensation through the social insurance system due to changes in regulations (Government Offices of Sweden, 2008). On average, the women had 7.8 years of sick leave (range $=1-16.9$ years). The women participated either in a multidisciplinary team assessment and multimodal intervention (TEAM) or in an ACT intervention. Both interventions were tailored to meet the individuals' needs and resources. The length of the interventions were individualized and could continue for up to 1 year.

TEAM. The multidisciplinary team consisted of a physician, psychologists, an occupational therapist, and a social worker. The TEAM developed a protocol that comprised assessment and treatment. The assessment phase started with each team member performing a 1.5- to 2-hr interview with the project participant. After the interviews, the case was discussed at a multidisciplinary team meeting with a focus on symptoms and their influence on the participant's function, resources, and challenges that had been identified, the team's overall assessment of the project participant's work ability, and probability of RTW. The team conference aimed to develop a treatment plan that included suggested 
interventions from one or more of the team members with the goal of improving the project participant's possibilities for RTW. The treatment, which started when the project participant had accepted the plan, could be evaluated and adjusted through discussions at weekly team meetings.

ACT. The ACT treatment was conducted by psychologists, and the protocol started with assessments through a clinical interview. The treatment began with a behavior analysis; mapping of relationships, leisure time, work, and physical activities; learning of new ways of accepting discomfort; and practice of self-accepting and self-care. The ACT intervention aimed at increasing the project participant's flexibility regarding obstacles to RTW.

Both the TEAM and ACT interventions were carried out through regular meetings between the professionals and the project participants. The meetings mostly took place at the project site, but the health care professionals also offered the possibility to meet with the women at their home or workplace.

Cooperation. Both the TEAM and the ACT interventions included cooperation with professionals from the SSIA and SPES. The professionals from the SSIA managed the rules and documents that govern the participant's sick leave to adapt these according to the individual's needs and the vocational rehabilitation process. The professionals from the SPES conducted assessments to identify the individual's need for support to RTW, offers of work training placement, and meetings with employers. A professional from the health care services participated together with the project participant in scheduled cooperation meetings with the SPES professional.

Control group. The control group received treatment as usual from the health care services and according to regular routines from SSIA and SPES. They were not offered assessment or treatment from the Vitalis project.

The Vitalis project, as well as its outcome for the project participants, has been presented in previous publications (Andersén et al., 2015, 2018a; Berglund et al., 2018; Finnes et al., 2021; Lytsy et al., 2017).

\section{Informants in the Interview Study}

To ensure that the informants in the interview study had experience of the Vitalis project, a strategic sampling method was used to include those with experience of daily work with the project participants. All rehabilitation professionals from the Department for Vocational Rehabilitation (except for the physician) and the professionals from the SSIA and SPES who collaborated with the Vitalis project were invited to the interview study (13 persons). The physician participated only in the initial assessment and not in the subsequent rehabilitation, and was therefore not invited to the study. All invited agreed to participate, and the sample included 12 women and one men, four professionals from the SSIA, four from the SPES, four from the health care services, and one from the social services. The sampling method also ensured that all occupational groups that were affiliated with the project were represented among the informants.

The informants from the health care services conducted the TEAM intervention (psychologists, occupational therapist, and social worker) and the ACT intervention (psychologists). The informants from the SSIA and SPES were associated with the Vitalis project as cooperation partners and participated in the planning of the individually based rehabilitation for participants in both ACT and TEAM interventions. The informants from the health care services were employed at the Department of Vocational rehabilitation where the Vitalis project was run. The informants from the SSIA and the SPES were appointed to represent their organization in collaboration with the Vitalis project. See Table 1 for a description of the study informants.

\section{Procedure and Data Collection}

Potential informants received a letter with information about the study, followed by a phone call asking for interest in participating in an interview. All invited professionals gave their oral consent to participate in the interview and to audio recordings, and were included in the study. An interview guide with open-ended questions was created for the study and included questions about the vocational rehabilitation process, the roles of the professionals, facilitators and barriers for the participating women to RTW, and the professionals' suggestions to improve the women's contact with the stakeholders to support their RTW.

The interviews were performed individually at the professionals' workplaces by the second author (A.L.H.) who is an experienced interviewer. The interviews lasted from 60 to $70 \mathrm{~min}$, were audio recorded, and transcribed verbatim.

\section{Data Analysis}

The interviews were analyzed with a manifest qualitative content analysis (Graneheim \& Lundman, 2004) using the following steps. The transcribed interviews were read through several times to get an overall understanding of the content. Because of the richness of the material, the interviews were initially divided into two content areas, which covered the pre-established areas of interest, namely, text relating to factors identified as facilitators and barriers for RTW. Thereafter, the second author identified meaning units (issues that arose from the interviews) within each of the content areas, condensed and coded the meaning units, 
Table I. Demographics of Study Interviewees.

\begin{tabular}{llllll}
\hline No & Gender & \multicolumn{1}{c}{ Profession } & Authority & Length of interview & \multicolumn{1}{c}{ Employed in Vitalis or cooperation partner } \\
\hline I & Female & Official & SSIA & $\mathrm{I} \mathrm{hr}$ & Cooperation partner \\
2 & Female & Official & SSIA & $\mathrm{I} \mathrm{hr}$ & Cooperation partner \\
3 & Female & Official & SSIA & $\mathrm{I} \mathrm{hr}$ & Employed in Vitalis \\
4 & Male & Official & SSIA & $\mathrm{I} \mathrm{hr}$ & Cooperation partner \\
5 & Female & Official & SPES & $\mathrm{I} \mathrm{hr}$ & Cooperation partner \\
6 & Female & Official & SPES & $\mathrm{I} \mathrm{hr}$ & Cooperation partner \\
7 & Female & Official & SPES & $\mathrm{I} \mathrm{hr}$ & Cooperation partner \\
8 & Female & Official & SPES & $\mathrm{I} \mathrm{hr}$ & Employed in Vitalis \\
9 & Female & Psychologist & Health care & $60-70 \mathrm{~min}$ & Employed in Vitalis \\
I0 & Female & Psychologist & Health care & $60-70 \mathrm{~min}$ & Employed in Vitalis \\
11 & Female & Physiotherapist & Health care & $60-70 \mathrm{~min}$ & Employed in Vitalis \\
12 & Female & Occupational therapist & Health care & $60-70 \mathrm{~min}$ & Employed in Vitalis \\
I3 & Female & Social worker & Social services & $60-70 \mathrm{~min}$ &
\end{tabular}

Note. SSIA = Swedish Social Insurance Agency; SPES = Swedish Public Employment Service.

and performed an initial categorization by comparing the codes for differences and similarities.

To strengthen credibility (Graneheim \& Lundman, 2004), all authors were involved in the analysis process. Furthermore, all of the authors continuously scrutinized and discussed the initial categorization until they reached a consensus about the structure of categories and themes. To achieve confirmability, authentic quotes are presented to illustrate the statements from which the categories were formed (Graneheim \& Lundman, 2004).

\section{Ethical Considerations}

The informants received both verbal and written information about the study, that participation was voluntary, that they could withdraw from the study at any time, and that all data would be treated confidentially in accordance with the Code of Ethics of the World Medical Association (Declaration of Helsinki). This study was conducted as part of a randomized controlled trial, the Vitalis project, which was approved by the Regional Ethical Review Board in Uppsala, Sweden (Dnr. 2010/088 and 2010/088/1), and is registered in ClinicalTrials.gov, ID NTC 03343457, November 5, 2017, retrospective registered. The interviews were conducted after the Vitalis project was concluded.

\section{Findings}

In this section, the term "informants" will be used for those interviewed in the interview study and the term "participants" for the women on long-term sick leave who took part in the Vitalis project.

Facilitators of RTW fell under two categories: cooperation between stakeholders and professions, and support for the individual. Figure 1 shows an overview of the categories and connected sub-categories.

\section{Facilitators for RTW}

\section{Cooperation between stakeholders and professions}

Mutual communication and learning about each other's roles and tasks. The close cooperation between professionals from different stakeholders brought exchange of knowledge and experience, which was viewed as an important part of the work. This exchange increased knowledge about both the regulatory frameworks and work approaches of the other stakeholders and the general situation of women on long-term sick leave.

When I'm with them [at meetings], they understand more when I can explain why the patient is acting in different ways, and I understand their limitations due to their regulatory frameworks and what they can accomplish. You learn this from each other.

The Vitalis project's work approach also resulted in more frequent contacts between the professionals from the health care services and the professionals from the SSIA and the SPES. One professional from the SSIA was employed by the project, and this was described as being helpful in the dialogue between the SSIA and the health care professionals. The composition of the health care multidisciplinary team was considered to bring a broader perspective on the project participants' situation on a general level. Furthermore, the informants described that the professionals' joint effort to investigate, facilitate, and find strategies improved the efficiency of their work.

Yes, to coordinate and to collaborate with the Social Insurance Agency and the Employment service, network meetings with primary health care or someone else . . . To try to build bridges when people can't manage for various reasons, whether it was pain or depression or whatever.

The increased cooperation between the involved rehabilitation stakeholders was an additional factor for improved 


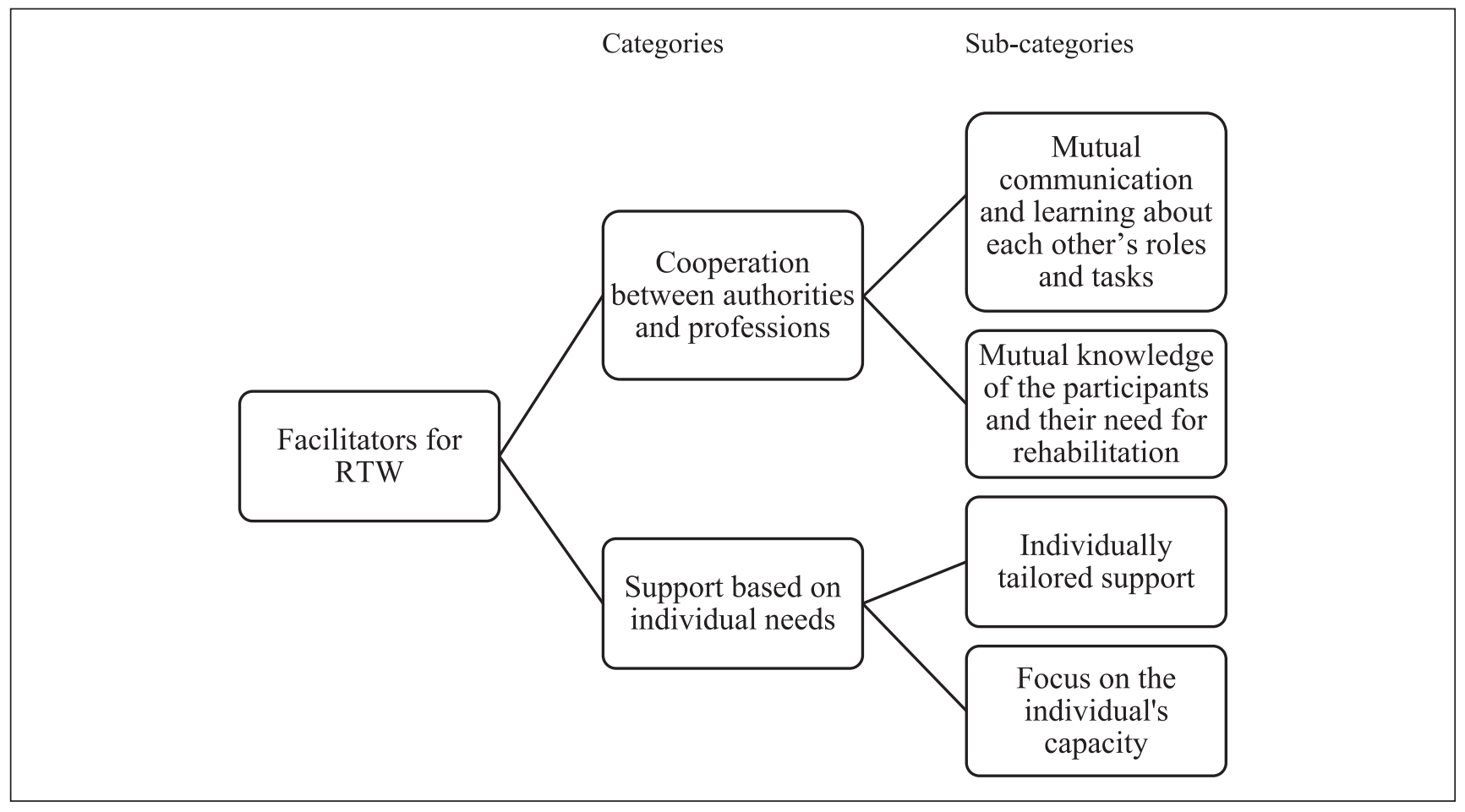

Figure I. Overview of categories and sub-categories identified as facilitators for RTW for women on long-term sick leave. Note. RTW = return to work.

efficiency. This was considered to be partly due to the fact that only a few professionals were involved in each participant's rehabilitation (only those associated with the project). This made it easier for them to get to know each other and to find time for meetings and planning. This restriction also helped to clarify the specific tasks of each profession as well as the rehabilitation process for the project participants.

Mutual knowledge of the project participants and their need for rehabilitation. The informants described that the joint efforts to complement each other's work to facilitate RTW for the project participants were characteristic of the working methods developed in the project. The professionals from different public stakeholders contributed with their specific competence and guidance to prepare the women for RTW.

Informants from the SSIA and SPES described that their knowledge about the complex situation that women on long-term sick leave may face had been insufficient before their participation in the cooperation project. Informants further added that they had been in need of knowledge about strategies to support the preparation and progress included in the RTW process. They also said that the participation of the health care multidisciplinary team in the project had increased their knowledge about both the project participant's specific problems and difficulties as well as relevant strategies. This knowledge was considered to enable professionals from the SPES to pursue individualbased work-oriented initiatives.

Yes, it's been much greater focus on working together with other professionals. It was something that we had as a . . an explicit goal to work with them. Both with other health care contacts ... this part to cooperate with the employment service which was included in our method. Previously, I haven't really seen it as a part of the method in the same way and I have worked more individually.

Furthermore, the informants from the SPES described that the working methods in the project were more effective compared with their regular work. The informants thought this was primarily due to the fact that the health care multidisciplinary team supported the project participants to be more prepared for work and that they had reflected on their future plans and had started a process of change.

They [the professionals, together with the participant] had often talked about what could be the next step. So, there was a great flexibility and the process had started.

Moreover, the informants from the health care services said that through their work in the project, they could focus more on RTW as part of the rehabilitation than in their regular work. They emphasized the need to address work issues 
at a timely stage in the rehabilitation process and to include support for RTW in their regular interventions. They also felt that work and activities generally improve health and that the project participants primarily needed activity instead of treatment.

Yes well, I usually take up as an advantage with this working method that it is more job related. So, when one works as a therapist, one has a very clear goal to work toward. Which is more to be able to function in a certain context . . . or environment ... well the workplace. Or on the job training or the employment services in contact with someone. This becomes clearer . . . I think it works better than before when I worked more to reduce symptoms.

\section{Support based on individual needs}

Individually tailored support. The analysis showed that the professionals considered the individual support to be important for the project participants' RTW. The support included individual treatment by one or more of the professionals from the health care multidisciplinary team and professionals from the SPES. The professionals from the health care worked with the project participants in their homes as well as at their workplaces to increase the possibility of detecting individual problems in the domestic environment and to discover and make adjustments at the workplace.

People are different, problems are different, and treatment should also be different. Some people don't talk about certain things but find it easier to talk about other things. For that reason, you have to give individually tailored rehabilitation. The goal is to get the persons back on their feet or at least closer to work.

Focus on the individual's capacity. The individual support focused on capacity, ability, and possibility based on the individual's situation. The informants described that to facilitate the project participants' RTW, they strived to increase the individual's confidence in his or her own capacity, ability to find strategies, and ability to handle various situations in everyday life. Through this focus, the professionals felt that the project participants were recognized and listened to due to their own unique situation and that they learned strategies to cope with situations in everyday life.

I'm thinking about the facilitators. Yes, perhaps it's that you believe in yourself and that you learn to manage and live with your obstacles. And give yourself what you need to feel as good as possible.

\section{Barriers to Returning to Work}

The informants identified four categories as barriers to RTW: stakeholders' different missions and goals, limited project duration, personal factors, and the labor market.
Figure 2 presents an overview of the categories and connected sub-categories.

\section{Stakeholders' missions and goals}

Different perspectives. The view of a concept such as work ability was reported to differ among professionals from the various stakeholders and that these differences influenced both the communication between the professionals and the decision making. The informants reported identifying feelings of frustration and confusion among the project participants and considered this to be consequences of the professionals' different views about the concept of work ability. The differences in conditions, views, and perspectives of the rehabilitation process were highlighted by all of the informants. So too were the differences in views about the women who participated in the project and their possibilities to participate in the vocational rehabilitation. The informants from the health care services described that the professionals from the SPES were specifically cautious in initiating work for the project participants.

And then, I think, we have had different perspectives if you look at SPES; if I start from myself, I see it as a person who wants to work and who is motivated. While SPES sees it as . . "Yes, but is this person able to get a job with what is required? Are there jobs for these persons based on their difficulties?"

The informants described that they focused on various parts of the rehabilitation process and that this affected the dialogue between the professionals from different stakeholders. The informants from the SPES were obliged to take specific account of the labor market and the employers' perspectives.

That, of course, the person wants a custom job close to home, preferably in the home. But there are no employers that hire you to do something in your home. And there is a clash, and a factor that I have to take into account that no one else will account for, they just pay attention to the unemployed individual.

Different working methods. The different working tasks and regulations that the informants needed to take into account were described as sometimes creating conflicts between them and that this could also create confusion and lack of clarity among the project participants. The work within the rehabilitation project was experienced as being transboundary, but sometimes there was a lack of skills among the professionals from SSIA and SPES and also conflicts between different responsibilities. The informants also described that different professions guarded their own territory in terms of expertise, qualifications, and competence.

It can be about territories. Who does what? Who has expertise in different areas? Those who have been trained in anything, do 




Figure 2. Overview of categories and sub-categories identified as barriers for RTW for women on long-term sick leave. Note. RTW = return to work.

these things best. But if there is a sense of security and respect within a group, we can help each other and although one ... exceeds one's competence, one can always try to focus on the patient's best interest. That's what's important, this should benefit the patient.

\section{Limited project duration}

Limited time for individual development. The informants had experienced that the time frame for the project duration was too short to create sustainable development among the project participants as they had been on sick leave for many years. The time aspect caused feelings of stress and anxiety among the professionals. This was because they felt that there was not always enough time to strengthen the project participants' confidence in their ability to work or to motivate them to start work training after many years of sick leave (on average 7.8 years).

The informants from the SPES, who were viewed as representing both the employee's and the employer's perspective, expressed frustration over the project participants' expectations of having suitable employment, as this did not always correspond to their skills or the jobs that were available. The limitation in project time also created difficulties for the professionals to assess what was the most appropriate times for the various interventions. This limitation was viewed as an obstacle for the project participants' opportunities to RTW, which was particularly noticeable for those included at the end of the project period.

The difficulty is to assess ... when to do something . . . to do the right thing at the right time, that's what's difficult in this job. When you work with people . . they might be in a crisis, and not at all ready to think about work.

Limited time to find suitable jobs. The difficulties in finding suitable employment and the lack of access for work training placements were described as obstacles for the project participants' RTW. These difficulties specifically concerned finding suitable work with the necessary flexibility and understanding for the project's target group.

Yes, [we need] a more flexible labor market. No matter how you treat a person or what you do to motivate, I think that if there aren't any places that are adapted for a person with a lower level of function, then we can't do much more . . . and I also believe that it includes ... a greater employer responsibility where they are more involved in this process.

The informants from the SPES emphasized the importance of preparations before work-oriented initiatives and 
that this could take a long time to complete. They stressed that the rehabilitation process needs to be started at the beginning of the sick leave. They had also found that there may be a need for preparations such as psychotherapy before transition to the SPES to identify the efforts needed for future work training or employment. They stated that the preparations and discussions about work should be an important part of the rehabilitation process, despite the individual's own perceived work-related obstacles.

It is a process that [should] start earlier [during the sick leave]. To think about what will happen later [after the sick leave]. [To raise] issues about work despite the symptoms, even though there are obstacles. So that the process starts much earlier, so that the person will be prepared.

\section{Labor market}

Limited access to suitable work opportunities. The informants described that the project's contact with the labor market and potential employers was insufficient, which limited the project participants' opportunities to have their work ability tested. There were some uncertainties as to whether the reason for the lack of work training was due to the labor market or to limitations in the project.

I think that what may have been an obstacle is that there was no connection to the labor market. Most of the people we met wanted to work, but there were no job opportunities. I think it's on a political level; I don't know how the project could have contributed. But I think, maybe all these efforts we have put in, I don't know if it has been an obstacle, but maybe we should have had a clearer focus on activity rather than rehabilitation and treatment.

It also created frustration among the professionals when the project participants were motivated and ready to start work training, but there was a lack of available work training places.

Yes ... and it's very frustrating that when you have started [the rehabilitation] and everything works great [for the participant] and then, there is no opportunity for employment, and there is no one who can help by providing an internship.

Professionals from the SPES were linked to the project, and they expressed frustration over their part in the project. They did not believe they could find work training places or employment opportunities for the project participants.

There is frustration that we don't deliver a job, an adapted job. And that's, again, the vision that the SPES just has a lot of unemployed people that we can get to, they don't realize that we have employers who we need to serve with staff. And this is another collision of expectations; we don't have jobs to give, we can only support people to apply for jobs.

\section{Personal factors}

Financial concerns. The informants described that their deteriorating income, a consequence of reaching the maximum number of days allowed for compensation from the social insurance system, raised concerns about their financial situation. Instead of focusing on the work-oriented activities offered within the project, the participants initially expanded their energy to try to resolve the financial situation. This affected their motivation and was considered as prolonging the rehabilitation process.

This group who had a major economic setback, they took a step backwards. Everyone took a step back at first because of the worry. But most of them could get up again, so to speak.

Personal and family-related problems. A complex social situation and family-related problems were described as other obstacles to RTW. Some project participants had adapted to the role of "being sick" and others had a complex family-related situation, which they felt led to difficulties in spending time outside of the home and away from the children. These factors were considered to cause additional major barriers to the possibilities of finding suitable work.

They can hardly get to the bus to go anywhere, have back pain, can't sit on a bus. Want to work, have a custom job close to home, preferable in the home, something with computers. There are no such jobs, and this has been very difficult.

\section{Discussion}

This is a descriptive qualitative study of professionals' perceptions of facilitators and barriers for RTW for women on long-term sick leave due to musculoskeletal pain and/or common mental disorder, who participated in a vocational rehabilitation project (the Vitalis project).

\section{Facilitators for RTW}

Our informants considered that the main facilitators for the increased employability and RTW were (a) the level of cooperation between the various vocational rehabilitation stakeholders, and (b) the level of individual support offered to project participants. Moreover, the collaboration between the SPES and the health care services contributed to an assessment of functional ability from both a medical and a psychological perspective in the assessment of the work ability process.

The close cooperation between the professionals and between the stakeholders enabled mutual dialogue and learning of each other's roles and tasks in relation to the target group. The informants perceived the cooperation as both broadening the skills needed to meet the project participant's need for rehabilitation and having contributed to 
these efforts becoming more efficient. In previous studies, a working dialogue between stakeholders and professionals included in vocational rehabilitation is found to both increase knowledge about each other (Gard \& Larsson, 2006; Gard \& Söderberg, 2004) and to develop mutual understanding and respect, which facilitates the cooperation between stakeholders (Pransky et al., 2010). An "adequate cooperation" between stakeholders is also found to support early RTW (Hoefsmit et al., 2014). Furthermore, in interviews with employees from various vocational rehabilitation stakeholders, Germundsson and Danermark (2012) found that respect between the professionals and recognition of the others' knowledge facilitated both the cooperation process and the vocational rehabilitation.

Our informants stressed the importance of systematic, multidisciplinary, and client-centered cooperation in vocational rehabilitation. An intervention with this approach, which included solution-oriented cooperation, has been shown to increase the number of working days after the intervention period for people with long-term sick leave compared with those who received conventionally organized rehabilitation, that is, rehabilitation that did not encompass solution-focused cooperation (Kärrholm et al., 2006). At a 6-year follow-up, the employment rates were still improved for those who participated in the multiprofessional cross-sector cooperation intervention compared with controls who received "the usual form of cooperation" (Jakobsson et al., 2010).

Previous studies have also shown the need for intensive support throughout the rehabilitation process and a holistic view of the individual. Hence, people's lives and daily routines are equally important for the rehabilitation efforts as the specific employment-related activities (Germundsson \& Danermark, 2012; Hein et al., 2005; Hillborg et al., 2010, 2013; Woodside et al., 2006). Some methods that incorporate individual and flexible support tailored to the individuals' needs have been found to be effective in the rehabilitation process for persons with mental health disabilities. This concerns individual placement support and supported employment (Luciano et al., 2014; Moll et al., 2003), ongoing support and work-related social skills training (Smith et al., 2017), and case management for unemployed persons (Selander \& Marnetoft, 2005). When support is tailored to the individual's needs, it may also strengthen the individual's positive perception of the working situation, a factor that is found to stimulate RTW (Hoefsmit et al., 2014). Furthermore, rehabilitation based on the individual's specific needs may increase his or her feelings of participation in the rehabilitation process and a sense of being acknowledged and listened to. These are factors that are found to strengthen the quality of the encounter with health professionals and its impact on rehabilitation and RTW (Sturesson et al., 2014).

The professionals in the Vitalis project focused on supporting the individual's strengths and capacities to strengthen their confidence in their own abilities. A trustful relationship and coaching, which can be mediated by showing confidence in the individual's ability, together with selfreliance and own responsibility, are found to be important factors for women with long-term sick leave in their decision making about RTW (Mårtensson \& Hensing, 2012). Trust in the individual's ability, conveyed from the staff to the individuals, can lay the foundation for positive contacts with professionals, which are found to be of greater importance than type of rehabilitation program (Östlund et al., 2003), and is also suggested to facilitate the process of RTW for women who are sick-listed (Müssener et al., 2007).

\section{Barriers to Returning to Work}

The informants perceived the main barriers for RTW to be both societal factors such as differences among the stakeholders' missions and goals, limitations in the project frames, and limited conditions for the target group to enter the labor market, as well as individual aspects such as the project participants' economic and family-related problems. Moreover, the Vitalis project lacked sufficient involvement of local employers.

The diversity of perspectives, goals, and working methods among the stakeholders involved in vocational rehabilitation found in the present study confirms the results from previous studies. Andersson et al. (2010) found different agendas and working methods, and administrative restrictions between the rehabilitation stakeholders. Johansson et al. (2010) reported absence of joint values, goals, efforts, and working methods. Previous studies found that the motives and goals for cooperation differed between the rehabilitation stakeholders and that the managers had difficulties implementing cooperation within their organizations (Ståhl et al., 2010, 2011).

When stakeholders within a Swedish project for vocational rehabilitation were studied (similar to the project in our study), the main barriers were found to be uncertainty (unclear goals, leadership, and roles), prioritizing own organization (both organizational and professional territoriality), formal and financial focus, and distrust and different perspectives (Wihlman et al., 2008). Moreover, they also reported lack of dialogue, lack of participation, and lack of learning between the stakeholders (Wihlman et al., 2008).

Furthermore, different rules and regulations for stakeholders (e.g., different rules on confidentiality and employment conditions) have been found to complicate the collaboration between the professionals (Hultberg et al., 2005; Söderberg et al., 2010). The rules and regulations may also change over time due to new political initiatives, which may create new barriers to collaboration over time.

Our informants perceived the project duration to be too short to gain sustainable development in this group of participants who had been on sick leave for many years. The 
limited project duration also caused problems in finding workplaces with the flexibility and understanding for the needs of this specific target group. These constraints regarding time have been found in previous research both from case managers, who reported project times as being too short to allow for time to place clients in a suitable job, and from the clients who stressed that the support they received for their job search was too brief (Lammerts et al., 2016). The timing has also been found to be important, in the sense of finding the optimal time in a sick leave process when measures have the best effect, as early interventions prove to be more effective than later ones for women on long-term sick leave (Marnetoft \& Selander, 2002).

The Vitalis project was set up according to a cooperation model, which focused on treatment and preparation, based on the individual's needs before a placement for work training was initiated. This was viewed as being a relevant model, as there are many factors influencing the RTW process. Both individual factors (physical, cognitive, emotional, and social) and the corresponding systems involved are important (the SSIA, SPES, workplace, and the health care services) and must be taken into consideration (Losiel et al., 2001).

How the stakeholders work, what decisions they make, and how they communicate and cooperate with each other will influence the RTW process, whereas a lack of cooperation and communication between them can be obstacles for the individuals' ability to RTW (Ekberg, 2014; Ståhl et al., 2011). Thus, it is important to identify factors related to stakeholders' systems, which individuals perceive as affecting their ability to RTW because these factors will affect how the individuals assess their own ability to overcome the obstacles (Corbiere et al., 2017). Involving the different stakeholders may increase the ability to address or overcome them. Research has found that long-term sick leave can lead to being marginalized from the labor market (Möller et al., 2012). As the women had been on sick leave for an extended period, it was important to have cooperation between stakeholders to avoid this risk of being marginalized and to increase their conditions for RTW.

Our informants considered it a problem that the project's contact with both the labor market in general and with potential employers was limited and that this reduced the opportunities to find work training places for the project participants to test their work ability. However, the informants were uncertain as to whether the lack of work training places was due to limitations in the project's structure or to societal factors beyond what this project could influence. Clermont et al. (2012) found that obstacles to RTW included lack of collaboration with and understanding from the employer, which made it difficult to gradually RTW, to be assigned to lighter duties, or to work at one's own pace. Furthermore, a newly published review concludes that when RTW is the goal after sick leave for common mental disorders, the workplace must be involved, regardless of the reason for the sick leave (Forskningsrådet för hälsa, arbetsliv och välfärd, 2020).

Employers' reluctance to hire people to work remotely (e.g., from home) using electronic technologies reported by the professionals from SPES may have changed since these interviews were conducted. More specifically, remote working increased in 2020 as social distancing was one of the strategies to prevent the spread of COVID-19 during the corona pandemic. Because of this experience, employers may be more likely to consider hiring employees with flexibility in work location, allowing employees to work remotely from home.

Factors such as financial concerns and personal and family-related problems were considered by the informants as possible barriers for the project participants' RTW. Concerns about the financial situation were seen as lowering the project participants' motivation to focus on work which contributed to a delay in the rehabilitation process. Moreover, a complex social situation combined with various familyrelated problems were also viewed as causing barriers to finding suitable jobs. Clermont et al. (2012) also found that factors such as unpredictability of one's situation, conviction that RTW will lead to a relapse, and loss of self-confidence were associated with negative RTW outcomes.

Despite these perceived barriers, participants in Vitalis actually demonstrated significant increases in employment outcomes, so despite perceived barriers, positive gains were made, and these gains actually sustained over time. However, it is unknown if these gains would have improved even more with more participants, if some of these perceived barriers were further addressed within the treatment design.

\section{Limitations}

The study has some limitations, which need to be addressed. The sample size was small, consisting of 13 interviewees working with women on sick leave for long periods. Furthermore, the sample was drawn from a single center implementing a vocational rehabilitation research project. Therefore, one should be cautious in interpreting results beyond the study sample. Despite these limitations, it is important to note that the sample was purposefully selected because the informants were professionals who worked daily on this vocational rehabilitation project and therefore had knowledge other professionals would not have. This purposeful sample is consistent with similar qualitative research designs.

\section{Implications for Practice}

It may be possible from the findings of this qualitative study to draw implications for intervention practice. The results show how different stakeholders can complement each other's knowledge and integrate their efforts to better support 
vocational rehabilitation participants. The improved dialogue between professionals from different stakeholders provides an opportunity to learn from each other and to gain better understanding of each other's role and missions. This is beneficial for both the professionals and the participants taking part in the vocational rehabilitation process.

The professionals from different stakeholders worked closely together and in collaboration with the project participants to support them during the vocational rehabilitation process. This interaction between professionals and participants in vocational rehabilitation has been found to have an important influence on the participants' perceived abilities, including their expectations about or belief in RTW (Andersén et al., 2018b).

A new finding from this study is that health care professionals can contribute to the assessment of work ability from a medical rehabilitation perspective, specifically by providing knowledge about how symptoms can affect work ability and setting reasonable goals for the vocational rehabilitation. This way of integrating medical knowledge was considered valuable by the professionals from the SSIA and the SPES as it may clarify what can be expected goals with the vocational rehabilitation and thereby reduce the risk for setbacks for the project participants. By gaining a better understanding of the project participant's strengths and needs, vocational rehabilitation professionals can develop better and more individually tailored vocational interventions leading to plausible and successful outcomes.

Informants talked about the need to better identify job opportunities for participants. This highlights the need to better engage local employers to contribute with work training placements and employments. Future research could explore ways to increase the employer's involvement in the vocational rehabilitation process and to study the conditions for vocational rehabilitation for men on long-term sick leave.

\section{Conclusion}

The close cooperation between the professionals and the individual support provided to the project participants were considered to be the main facilitators for RTW for women on long-term sick leave. The cooperation was found to enable mutual dialogue and gave an opportunity to learn about each other's roles and tasks as well as about the project participants' need for rehabilitation.

The main barriers were differences among the various stakeholders' missions and goals, time limit for the project duration, and limited conditions for the target group to enter the labor market due to a lack of sufficient involvement by local employers. Moreover, the project participants' personal aspects such as financial and family-related problems were seen as barriers for RTW.

Some of these results are in line with previous research in the field such as the importance of collaboration between the professionals and the need to focus on the individual's resources and needs. This study highlights the value of including health care professionals in vocational rehabilitation to benefit from their specific knowledge of the target group including their diagnoses as well as their strengths and needs. Moreover, it highlights the need to incorporate collaboration with employers and align with the local labor market when developing new vocational rehabilitation interventions.

\section{Declaration of Conflicting Interests}

The author(s) declared no potential conflicts of interest with respect to the research, authorship, and/or publication of this article.

\section{Funding}

The author(s) disclosed receipt of the following financial support for the research, authorship, and/or publication of this article: This work was funded by REHabilitering och SAMordning (REHSAM), under Grant RS2011/010, a research program financed by The Swedish Ministry of Health and Social Affairs, The Social Insurance Agency, The Swedish Association of Local Authorities and Regions, and Vårdalstiftelsen. The funding organizations had no role in the planning, execution, or analyses of the study.

\section{Supplemental Material}

The interviews in this study (in Swedish language) are available on request from the corresponding author. The interviews are not publicy available due top ethical reasons.

\section{References}

Andersén, Å., Larsson, K., Lytsy, P., Berglund, E., Kristiansson, P., \& Anderzén, I. (2018a). Strengthened general self-efficacy with multidisciplinary vocational rehabilitation in women on long-term sick leave. Journal of Vocational Rehabilitation, 28(4), 691-700. https://doi.org/10.1007/s10926-017-9752-8

Andersén, Å., Larsson, K., Lytsy, P., Kristiansson, P., \& Anderzén, I. (2015). Predictors of self-efficacy in women on long-term sick leave. International Journal of Rehabilitation Research, 38, 320-326. https://doi.org/10.1097/MRR.0000000000000129

Andersén, Å., Ståhl, C., Anderzén, I., Kristiansson, P., \& Larsson, L. (2018b). Positive experiences of a vocational rehabilitation intervention for individuals on long-term sick leave, the Dirigo project: A qualitative study. BMC Public Health, 17, Article 790. https://doi.org/10.1186/s12889-017-4804-8

Andersson, J., Axelsson, R., Axelsson Bihari, S., Eriksson, A., \& Åhgren, B. (2010). Collaboration in work-oriented rehabilitation: A compilation of knowledge and experience in the field. Nordic University of Public Health. (In Swedish)

Angelov, N., Johansson, P., Lindahl, E., \& Lindström, E.-A. (2011). Women's and men's sickness absence. Institute for Evaluation of Market and Education Policy. (In Swedish)

Berglund, E., Anderzén, I., Andersén, Å., Carlsson, L., Gustavsson, C., Wallman, T., \& Lytsy, P. (2018). Multidisciplinary intervention and acceptance and commitment therapy for returnto-work and increased employability among patients with mental illness and/or chronic pain: A randomized controlled 
trial. International Journal of Environmental Research and Public Health, 15(11), E2424. https://doi.org/10.3390/ ijerph15112424

Clermont, E. D., Bourbonnais, R., Frémont, P., Rossignol, M., Stock, S. R., \& Laperrière, E. (2012). Obstacles to and facilitators of return to work after work-disabling back pain: The workers' perspective. Journal of Occupational Rehabilitation, 23, 280-289. https://doi.org/10.1007/s10926-012-9399-4

Corbiere, M., Negrini, A., Durand, M.-J., St-Arnaud, L., Briand, C., Fassier, J. B., Loisel, P., \& Lachance, J. P. (2017). Development of the Return-to-Work Obstacles and SelfEfficacy Scale (ROSES) and validation with workers suffering from a common mental disorder or musculoskeletal disorder. Journal of Occupational Rehabilitation, 27, 329341. 10.1007/s10926-016-9661-2

Deutreux, J., \& Viksten, A. (2004). Reasons for difference in women's and men's sick leave patterns: An overview of knowledge. Riksförsäkringsverket. (In Swedish)

Ekberg, K. (2014). Den relativa arbetsförmågan: teoretiska och praktiska perspektiv [The relative workability: Theoretical and practical perspectives]. Studentlitteratur.

Finnes, A., Anderzén, I., Pingel, R., Dahl, J. A., Molin, L., \& Lytsy, P. (2021). Comparing the efficacy of multidisciplinary assessment and treatment or acceptance and commitment therapy, with treatment as usual on health outcomes in women on long-term sick leave-A randomised controlled trial. International Journal of Environmental Research and Public Health, 18, 1754. https://doi.org/org/10.3390/ijerph18041754

Fishbain, D. A., Cutler, R., Rosomoff, H., \& Rosomoff, R. S. (1997). Chronic pain-associated depression: Antecedent or consequence of chronic pain? A review. The Clinical Journal of Pain, 13(2), 116-137. https://doi.org/10.1097/00002508199706000-00006

Forskningsrådet för hälsa, arbetsliv och välfärd. (2020). En kunskapsöversikt. Psykisk ohälsa, arbetsliv och sjukfrånvaro [A knowledge overview. Mental illness, working life and sick leave].

Gard, G., \& Larsson, A. (2006). How can cooperation between rehabilitation professionals in rehabilitation planning be improved? A qualitative study from the employer's perspective. Work, 26(2), 191-196.

Gard, G., \& Söderberg, S. (2004). How can a work rehabilitation process be improved? A qualitative study from the perspective of social insurance officers. Disability \& Rehabilitation, 26(5), 299-305. https://doi.org/10.1080/09638280310001647624

Germundsson, P., \& Danermark, B. (2012). Vocational rehabilitation, interagency collaboration and social representations. Work, 42, 507-517. https://doi.org/10.3233/WOR-2012-1382

Government Offices of Sweden. (2008). Regeringens proposition 2007/08:136. En reformerad sjukskrivningsprocess för ökad återgång $i$ arbete [Government proposition 2007/08: 136. A reformed sick leave process to increase return to work]. https://data.riksdagen.se/fil/C0AE4CB9-2E01-4593-A88146CFC39D4A5

Graneheim, U. H., \& Lundman, B. (2004). Qualitative content analysis in nursing research: Concepts, procedures and measures to achieve trustworthiness. Nurse Education Today, 24(2), 105-112. https://doi.org/10.1016/j.nedt.2003.10.001

Hein, S., Lustig, D. C., \& Uruk, A. (2005). Consumers' recommendations to improve satisfaction with rehabilitation services: A qualitative study. Rehabilitation Counseling Bulletin, 49(1), 29-39. https://doi.org/org/10.1177/00343552050490010401

Henderson, M., Harvey, S. B., Overland, S., Mykletun, A., \& Hotopf, M. (2011). Work and common psychiatric disorders. Journal of the Royal Society of Medicine, 104, 198-207. https://doi.org/10.1258/jrsm.2011.100231

Hillborg, H., Danermark, B., \& Svensson, T. (2013). Professionals' perceptions of and views bout vocational rehabilitation for people with psychiatric disabilities. Work, 44, 471-480. https://doi.org/10.3233/WOR-131518

Hillborg, H., Svensson, T., \& Danermark, B. (2010). Towards the working life? Experiences in a rehabilitation process for people with psychiatric disabilities. Scandinavian Journal of Occupational Therapy, 17(2), 149-161. https://doi. org/10.1080/11038120902906303

Hoefsmit, N., Houkes, I., \& Nijhuis, F. (2014). Environmental and personal factors that support early return-to-work: A qualitative study using the ICF as a framework. Work, 48, 203-215. https://doi.org/10.3233/WOR-131657

Hultberg, E., Glendinning, C., Allebeck, P., \& Lönnroth, K. (2005). Using pooled budgets to integrate health and welfare services: A comparison of experiments in England and Sweden. Health and Social Care in the Community, 13(6), 531-541. https://doi.org/10.1111/j.1365-2524.2005.00585.x

Jakobsson, B., Ekholm, J., Bergroth, A., \& Ekholm, K. S. (2010). Improved employment rates after multiprofessional crosssector cooperation in vocational rehabilitation: A 6-year follow-up with comparison groups. International Journal of Rehabilitation Research, 33(1), 72-80. https://doi. org/10.1097/MRR.0b013e32832fea0a

Johansson, P., Aydin, E., Bergendorff, S., Granqvist, N., Josephson, M., \& Sohlberg, I. (2010). Work-oriented rehabilitation (Report No. 7 to the Parliamentary Social Insurance Investigation). Inspection for Social Insurance. (In Swedish)

Kärrholm, J., Ekholm, K., Jakobsson, B., Ekholm, J., Bergroth, A., \& Schuldt, K. (2006). Effects on work resumption of a co-operation project on vocational rehabilitation. Systematic, multi-professional, client-centered and solution-oriented cooperation. Disability and Rehabilitation, 28(7), 457-467. https://doi.org/10.1080/09638280500198063

Kvale, S., \& Brinkmann, S. (2009). InterViews: Learning the craft of qualitative research interviewing ( $2 \mathrm{nd} \mathrm{ed}$.). SAGE.

Lammerts, L., Schaafsma, F. G., van Mechelen, W., \& Anema, J. R. (2016). Execution of a participatory supportive return to work program within the Dutch social security sector: A qualitative evaluation of stakeholders' perceptions. BMC Public Health, 16, Article 323. https://doi.org/10.1186/s12889-0162997-x

Linder, J., Schüldt Ekholm, K., Jansen, G. B., Lundh, G., \& Ekholm, J. (2009). Long-term sick leavers with difficulties in resuming work: Comparisons between psychiatricsomatic comorbidity and monodiagnosis. International Journal of Rehabilitation Research, 32(1), 20-35. https://doi. org/10.1097/MRR.0b013e328306351d

Loisel, P., \& Anema, J. R. (2013). Handbook of work disability: Prevention and management. Springer.

Losiel, P., Durand, M.-L., Berthelette, D., Vezina, N., Baril, R., Gagnon, D., Lariviére, C., \& Tremblay, C. (2001). Disability prevention. New paradigm for the management 
of occupational back pain. Disease Management and Health Outcomes, 9(7), 351-360. https://doi.org/10.2165/00115677200109070-00001

Luciano, A., Drake, R. E., Bond, G. R., Becker, D. R., Song, E. C., Lord, S., Swarbrick, P., \& Swanson, S. J. (2014). Evidencebased supported employment for people with severe mental illness: Past, current, and future research. Journal of Vocational Rehabilitation, 40, 1-13. https://doi.org/10.3233/JVR-130666

Lytsy, P., Carlsson, L., \& Anderzén, I. (2017). Effectiveness of two vocational rehabilitation programmes in women on long-term sick leave due to pain syndrome or mental illness: 1-year follow-up of a randomized controlled trial. Journal of Rehabilitation Medicine, 49(2), 170-177. https://doi. org/10.2340/16501977-2188

Marnetoft, S.-U., \& Selander, J. (2002). Long-term effects of early versus delayed vocational rehabilitation: A four-year followup. Disability and Rehabilitation, 24(14), 741-745. https:// doi.org/10.1080/09638280210124338

Mårtensson, L., \& Hensing, G. (2012). Experiences of factors contributing to women's ability to make informed decisions about the process of rehabilitation and return to work: A focus group study. Work, 43, 237-248. https://doi.org/10.3233/ WOR-2012-1397

Moll, S., Huff, J., \& Detwiler, L. (2003). Supported employment: Evidence for a best practice model in psychosocial rehabilitation. Canadian Journal of Occupational Therapy, 5(70), 298-310. https://doi.org/10.1177/000841740307000506

Möller, J., Hultin, H., \& Lindholm, C. (2012). Consequences of sick leave: A longitudinal study of the effects of sick leave on long-term sick leave and labor market position (Final Report Project dnr 090247 to AFA Health Insurance). Karolinska Institutet, Department of Global Public Health.

Müssener, U., Svensson, T., Söderberg, E., \& Alexanderson, K. (2007). Encouraging encounters: Sick-listed persons' experiences of interactions with rehabilitation professionals. Social Work in Health Care, 46, 71-78. https://doi.org/10.1300/ j010v46n02_05

Östlund, G., Borg, K. E., Wide, P., Hensing, G., \& Alexandersson, K. (2003). Clients' perceptions of contact with professionals within healthcare and social insurance officers. Scandinavian Journal of Public Health, 31, 275-282. https:// doi.org/10.1080/14034940210165037

Pransky, G., Shaw, W. S., Loisel, P., Hong, Q. N., \& Desorcy, B. (2010). Development and validation of competencies for return to work coordinators. Journal of Occupational Rehabilitation, 20(1), 41-48. https://doi.org/10.1007/s10926-009-9208-x

Selander, J., \& Marnetoft, S.-U. (2005). Case management in vocational rehabilitation: A case study with promising results. Work, 24, 297-304.

Smith, D. L., Atmatzidis, K., Capogreco, M., Lloyd-Randolfi, D., \& Seman, V. (2017). Evidence-based interventions for increasing work participation for persons with various disabilities: A systematic review. Occupation, Participation and Health, 37(25), 3S-13S. https://doi.org/10.1177/1539449216681276

Söderberg, E., Vimarlund, V., \& Alexandersson, K. (2010). Experiences of professionals participating in inter-organisational cooperation aimed at promoting clients' return to work. Work, 35(2), 143-151. https://doi.org/10.3233/WOR-20100966

Ståhl, C., Svensson, T., \& Ekberg, K. (2011). From cooperation to conflict? Swedish rehabilitation professionals' experiences of interorganizational cooperation. Journal of Occupational Rehabilitation, 21, 441-448. https://doi.org/10.1007/s10926010-9281-1

Ståhl, C., Svensson, T., Petersson, G., \& Ekberg, K. (2010). A matter of trust? A study of coordination of Swedish stakeholders in return-to-work. Journal of Occupational Rehabilitation, 20, 299-310. https://doi.org/10.1007/s10926-009-9205-0

Sturesson, M., Edlund, C., Falkdal, A. H., \& Bernspång, B. (2014). Healthcare encounters and return to work: A qualitative study on sick-listed patients' experiences. Primary Health Care Research \& Development, 15, 464-475. https:// doi.org/10.1017/S1463423614000255

Swedish Public Employment Service. (2021). Extra stöd [Additional support]. https://arbetsformedlingen.se/otherlanguages/english-engelska/extra-stod

Swedish Social Insurance Agency. (2007). Långtidssjukskrivna: demografi, arbete, yrke, diagnos, sjukpenningrätt och återgång $i$ arbete 2003, 2005 och 2006 [Long-term sick leave: Demographics, work, occupation, diagnosis, sickness benefit entitlement and return to work 2003, 2005 and 2006] [The Swedish Social Insurance Agency reports 2007].

Swedish Social Insurance Agency. (2015). Sjukskrivningar 60 dagar eller längre. En beskrivning av sjukskrivna åren 1999 - 2014 efter kön, ålder, arbetsmarknadsstatus, sjukskrivningslängd och diagnospanorama [Sick leave 60 days or longer: A description of those on sick leave in 1999-2014 by sex, age, labor market status, occupation, sick leave length and diagnosis panorama] [Social Insurance Report 2015].

Swedish Social Insurance Agency. (2021). Arbetslivsinriktad rehabilitering [Vocational rehabilitation]. https://www.forsakringskassan.se/halso-och-sjukvarden/sjukdom-och-skada/ arbetslivsinriktad-rehabilitering

Wihlman, U., Stålsby Lundborg, C., Axelsson, R., \& Holmström, I. (2008). Barriers of inter-organisational integration in vocational rehabilitation. International Journal of Integrated Care, 8, 1-12. https://doi.org/10.5334/ijic.234

Woodside, H., Schell, L., \& Allison-Hedge, J. (2006). Listening for recovery: The vocational success of people living with mental health. Canadian Journal of Occupational Therapy, 73, 36-43. https://doi.org/10.2182/cjot.05.0012 